\title{
Influencing Factors of Steel Slag/Blast Furnace Slag Based Solidifying Agents for Total Tailings Paste Backfill
}

\author{
Man-Chao LIU ${ }^{1, a}$, Feng-Qing ZHAO ${ }^{2,}$ b* \\ ${ }^{1}$ Hebei University of Science \& Technology, Shijiazhuang 050018, China \\ ${ }^{2}$ Hebei Engineering and Research Center of Solid Waste Utilization, Shijiazhuang 050018, China \\ a352293673@qq.com, 'bhaofq3366@126.com \\ ${ }^{*}$ Corresponding author
}

Keywords: Steel Slag, Blast Furnace Slag, Tailings, Cemented Backfilling Materials, Solidifying Agent.

\begin{abstract}
There exist synergistic effect between steel slag and blast furnace slag in preparation of solidifying agent for total tailings backfill. By investigating the effect of various activators, the proportioning of the solidifying agent was obtained: steel slag $35 \%$, blast furnace slag $35 \%$, Portland cement $10 \%$, desulfurization gypsum $10 \%$, calcium chloride $6 \%$, anhydrous sodium sulfate $2 \%$ and calcium oxide $2 \%$. The results show that compressive strength of specimens reaches $2.83 \mathrm{MPa}$, with the mass ratio of tailings and the solidifying agent being 1:5. It can be used to substitute Portland cement in total tailings backfill for goaf.
\end{abstract}

\section{Introduction}

With the rapid development of iron and steel industry in recent years, the demand for iron ore are increasing. After a long period exploitation, there left a lot of different goafs in mine area. In order to ensure safe production and protect the environment, we must take measures to backfill the goaf. Steel slag is the by-product of the steel production, which accounts for a proportion of approximately $15 \%$ $-20 \%$ by mass of the steel output. The accumulation of steel slag is also big, which not only occupies large area of land but also leads to the environmental pollution $[1,2]$. Tailing is another solid waste, whose accumulation has been more than eight billion tons in China alone. However, the utilization ratio of the tailings is only about $10 \%$ [3]. As for steel slag, the utilization starts relatively late in China, and the rate of utilization is only $20 \%-30 \%$ at present [4]. With the attention of the society on the environment, more and more attention has been paid on tailings and steel slag utilization these years [5,6]. Just like blast furnace slag, a by-product of iron-making process, steel slag has also experienced similar thermal history, and has similar mineral compositions as cement.

Portland cement is a traditional solidifying agent for backfilling, accounting for more than $75 \%$ of backfilling cost, which seriously restricts the use in mine backfill. Considering that the steel slag and blast furnace slag possess similar minerals to cement, have potential cementitious activity, which could be activated by mechanical grinding and chemical [7-9] to substitute cement in tailings backfill purpose.

In this work, we used steel slag and blast furnace slag as material, by fine grinding, adding some activators, to prepare a low-cost waste based cementing material for total tailings backfill process.

\section{Materials and Methods}

\section{Raw Materials}

In this study, Portland cement and activate agent are commercially available. Steel slag and tailing are from Zunhua Comprehensive Utilization of Solid Waste Corp. The specific surface area of steel slag is around $420-450 \mathrm{~m}^{2} / \mathrm{kg}$, and blast furnace slag about $380-410 \mathrm{~m}^{2} / \mathrm{kg}$. Chemical compositions of steel slag (SS), blast furnace slag (BFS) and tailing are given in Tab. 1.

It was confirmed by experiment that both steel slag and blast furnace slag contain $\mathrm{C}_{2} \mathrm{~S}$ and $\mathrm{C}_{3} \mathrm{~S}$, which have the potential cementitious activity. 


\section{Methods}

Steel slag was mixed with blast furnace slag and activator, ground to desired fineness in a laboratory type ball mill, add water. Water-cement ratio was fixed at 0.50 and cement-sand ratio at 1:3. The test specimens $(40 \mathrm{~mm} \times 40 \mathrm{~mm} \times 160 \mathrm{~mm})$ are prepared according to desired composition. Then take out the specimens after final set, cured for 24 hours under the condition of $55^{\circ} \mathrm{C}$ or standard cured 24 days to test the mechanical strength and other properties. Each mechanical strength value is the average of every 3 samples.

Tab. 1 Chemical composition of steel slag, blast furnace slag and tailing [\%]

\begin{tabular}{ccccccccc}
\hline Material & $\mathrm{SiO}_{2}$ & $\mathrm{MgO}$ & $\mathrm{CaO}$ & $\mathrm{Al}_{2} \mathrm{O}_{3}$ & $\mathrm{Fe}_{2} \mathrm{O}_{3}$ & $\mathrm{MnO}$ & $\mathrm{F}-\mathrm{CaO}$ & Loss on ignition \\
\hline $\mathrm{SS}$ & 15.67 & 9.01 & 29.82 & 8.47 & 28.71 & 6.09 & 0.1 & 2.13 \\
BFS & 39.05 & 8.47 & 30.98 & 2.53 & 13.65 & 1.15 & - & 4.17 \\
tailing & 58.49 & 4.80 & 6.69 & 11.70 & 12.25 & 0.16 & - & 5.91 \\
\hline
\end{tabular}

\section{Results and Discussion}

\section{Effect of the Mass Ratio of Steel Slag and Blast Furnace Slag}

We adjust the mass ratio of steel slag and blast furnace slag, by 1:0, 1:1, 1:2, 1:3, 0:1. The results are shown in Fig.1.

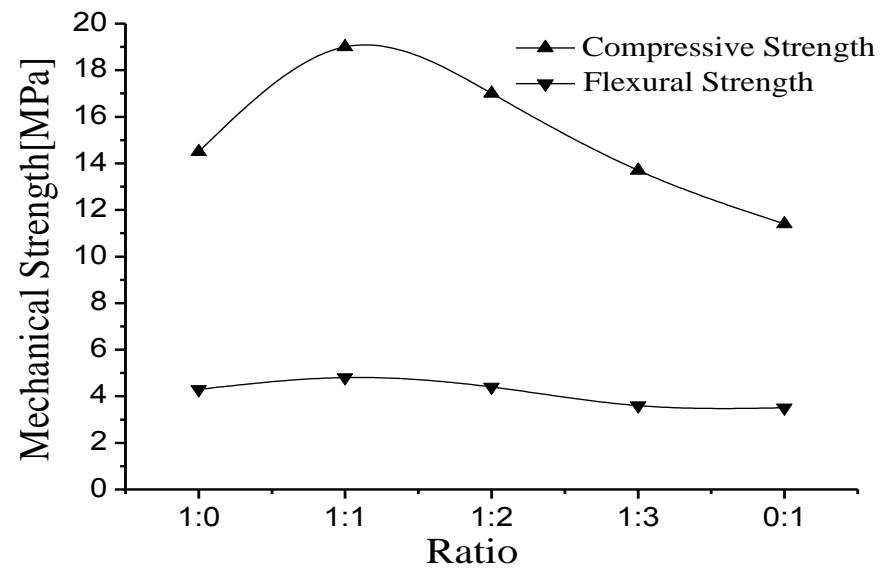

Fig. 1 Effect of the mass ratio of steel slag and blast furnace slag

It shows in Figure 1 that with the increase of the steel slag, mechanical strengthen of the sample increase at first and decrease later, and has a maximum value, when the mass ratio of steel slag and blast furnace slag reaches $1: 1$. On this condition, the compressive strength is $19 \mathrm{MPa}$ and flexural strength 4.8MPa.

\section{The Effect of Calcium Salts}

Three kinds of calcium salts including desulfurization gypsum (A), calcium chloride (B) and calcium carbonate $(\mathrm{C})$ were used as activator. The ratio of steel slag and blast furnace slag is 1:1 and Portland cement is fixed at $10 \%$. The dosage of calcium salts changes from 0 to $14 \%$. Mechanical strength values of the samples are shown in Tab. 2.

It is known from table 2 that calcium salts obviously improve the mechanical properties of the system. When the dosages of desulfurization gypsum and calcium chloride are $10 \%$ and $6 \%$, respectively, the compressive strength of the sample reaches $15.3 \mathrm{MPa}$. Compared with the desulfurization gypsum and calcium chloride, calcium carbonate shows less effect on the strength of the system. It can be deduced that 
the alkali condition promote the decomposition of steel slag and blast furnace slag, forming C-S-H and ettringite with the gypsum present in the cementing system, which contribute most to the mechanical strength of the samples.

Tab. 2 Effect of calcium salts on compressive strength of the solidifying agent

\begin{tabular}{cccc}
\hline $\begin{array}{c}\text { Dosage of calcium salt } \\
{[\%]}\end{array}$ & A & Compressive Strength [MPa] & C \\
\hline 0 & 5.9 & B & 3.7 \\
2 & 9.8 & 4.4 & 4.0 \\
4 & 12.2 & 7.6 & 4.5 \\
6 & 13.5 & 10.5 & 4.7 \\
8 & 13.4 & 15.3 & 4.9 \\
10 & 15.3 & 15.1 & 4.4 \\
12 & 15.0 & 14.8 & - \\
14 & 14.7 & - & - \\
\hline
\end{tabular}

\section{The Effect of Sodium Sulfate}

Anhydrous sodium sulfate and sodium aluminate were used as activator. The dosage of anhydrous sodium sulfate is 0 to $2.8 \%$, sodium aluminate 0 to 5\%. The results are shown in Tab. 3 and Tab. 4 .

Tab. 3 Influence of different dosage of sodium sulfate on the solidifying agent

\begin{tabular}{|c|c|}
\hline Dosage of anhydrous sodium sulfate [\%] & Compressive Strength [MPa] \\
\hline 0 & 3.7 \\
\hline 0.4 & 4.3 \\
\hline 0.8 & 5.7 \\
\hline 1.2 & 6.3 \\
\hline 1.6 & 6.7 \\
\hline 2.0 & 7.9 \\
\hline 2.4 & 6.6 \\
\hline 2.8 & 6.3 \\
\hline $\begin{array}{l}\text { Tab. } 3 \text { shows that when anhydrous sodium } \\
\text { solidifying agent reaches the highest value, i.e. } \\
\text { decrease of the solidifying agent in compressive } \\
\text { From Table } 4 \text { we can see that sodium alun } \\
\text { solidifying agent, thus it will be deleted in the a }\end{array}$ & $\begin{array}{l}\text { th is } 2 \% \text {, the compressive stre } \\
\text { ow or too high of the content } \mathrm{w} \\
\text { effect on the mechanical stre }\end{array}$ \\
\hline \multicolumn{2}{|c|}{ Tab. 4 Effect of dosage of sodium aluminate on solidifying agent } \\
\hline Dosage of sodium aluminate [\%] & Compressive Strength [MPa] \\
\hline 0 & 3.7 \\
\hline 1 & 3.7 \\
\hline 2 & 3.7 \\
\hline 3 & 4.2 \\
\hline 4 & 4.0 \\
\hline 5 & 3.5 \\
\hline
\end{tabular}




\section{Effect of Calcium Oxide}

Calcium oxide provides the alkali condition the solidifying agent needed to hydrate. The content of calcium oxide is $0,1 \%, 2 \%, 3 \%, 4 \%, 5 \%$, and the results are shown in Tab. 5 .

Tab. 5 Effect of different dosage of calcium oxide on solidifying agent

\begin{tabular}{cc}
\hline Dosage of calcium oxide [\%] & Compressive Strength[MPa] \\
\hline 0 & 3.5 \\
1 & 10.0 \\
2 & 10.9 \\
3 & 11.1 \\
4 & 11.2 \\
5 & 12.1 \\
\hline
\end{tabular}

It shows in Table 5 that the addition of calcium oxide significantly increases the mechanical properties of the solidifying agent. As calcium oxide content is $1 \%$, the compressive strength value increases from $3.5 \mathrm{MPa}$ to $10.0 \mathrm{MPa}$. The reasonable dosage of calcium oxide is $2 \%$.

\section{The Application of the Solidifying Agent}

Based on the results above, the proportioning of the solidifying agent was designed: steel slag 35\%, blast furnace slag 35\%, Portland cement $10 \%$, desulfurization gypsum $10 \%$, calcium chloride $6 \%$, anhydrous sodium sulfate $2 \%$ and calcium oxide $2 \%$. The proportioning was used to practical backfill to be testified.

The solidifying agent obtained was mixed with tailings in mass ratio of 1:5, adding water to form slurry concentration at $70 \%$ (solid content), which can be used backfill of goaf. The compressive strength values (28d) reaches $2.83 \mathrm{MPa}$, and satisfy the backfilling requirements of goaf.

\section{Conclusions}

By mechanical grinding and chemical activation, various factors on the solid based solidifying agent were investigated. The proportioning of the solidifying agent was obtained: steel slag 35\%, blast furnace slag $35 \%$, Portland cement $10 \%$, desulfurization gypsum $10 \%$, calcium chloride $6 \%$, anhydrous sodium sulfate $2 \%$ and calcium oxide $2 \%$.

The solidifying agent can be used as substitute for Portland cement in backfilling process, and shows higher mechanical properties, which can satisfy the backfill requirements of different goafs.

It should be noted that most of the materials used in the solidifying agent are solid waste, which provides an ideal approach for utilization of the solids.

\section{References}

[1] F.Q. Zhao, W. Ni, H.J. Wang, et al. Activated fly ash/slag blended cement, J. Resources Conservation \& Recycling. 52 (2007) 303-313.

[2] F.Q. Zhao, J. Zhao, H.J. Liu. Autoclaved brick from low-silicon tailings, J. Construction \& Building Materials. 23 (2009) 538-541.

[3] H. Che, W.G. Shen, L. Shan, et al. Situation of discharge and comprehensive utilization of iron tailings domestic and abroad, J. Concrete. 28 (2012) 88-92.

[4] T.S. Zhang, F.T. Liu, J.W. Wang, et al. Recent Development of Steel Slag Stability and Activating Activity, J. Bulletin of the Chinese Ceramic Society. 26 (2007) 980-984. 
[5] J.P. Liu, D.Q. Guo, J.Y. Zhu, et al. Status and development of the comprehensive utilization of the steel slag at Baosteel, J. Baosteel Technical Research. 05 (2011) 15-19.

[6] J.D. Liu, Y.A. Guo. Discussion on the resource regeneration routine steel slag, J. Henan Metallurgy. 22 (2004) 30-32.

[7] L.S. Yi, J. Wen. Research status and progress on steel slag activity excitation technology, J. Bullentin of the Chinese Ceramic Society. 32 (2013) 2057-2062.

[8] P.G. Li, F.Q. Zhao, Z. Ma. Improving the volume stability of steel slag for construction and building materials, J. Advanced Materials Research. 936 (2014) 1399-1403.

[9] Q. Li, F.Q. Zhao, H. Li, et al. Study on durability of blast-furnace slag and steel slag Cementing Material, J. China Concrete \& Cement Products. 1 (2011) 23-27. 